\title{
Evaluating feasibility of modified drilling waste materials in flexible base course construction
}

\author{
Chang Seon Shon, Cindy K. Estakhri, Dongoun Lee, Dichuan Zhang
}

- School of Engineering

\begin{abstract}
The study focuses on the evaluation of the engineering properties of modified drilling waste materials (MDWMs) as base course materials in roadway construction. This goal was accomplished by two main laboratory test evaluations of the MDWMs which are the basic material characterization and the performance evaluation of base course material. Material characterization results of the MDWMs indicate that they are relatively high $\mathrm{pH}$, low plastic, and clay sand materials, mainly consisting of quartz and barite and belonging to Grade 4 category in Texas Department of Transportation (TxDOT) Item 247 Flexible Base Aggregate. The unconfined compressive strength (UCS), triaxial compressive strength, indirect tensile strength, moisture susceptibility, and seismic modulus test data show that the untreated MDWM is lower than many of these requirements and is not a granular base material when compared with the typical base course requirements identified in the Item 247. However, evaluation of the MDWMs with $3 \%$ cement treatment in the laboratory showed good performance without sacrificing their abilities as proper base course materials and satisfied the requirements of Class M base as per TxDOT Item 276. However, it may be necessary that the quality control of this material be monitored in order to achieve consistent moisture content and gradation. Moreover, further work to establish optimum stabilizer content and type would be recommended for this material.
\end{abstract}

Original language $\quad$ English

Pages (from-to) $\quad 79-86$

Number of pages $\quad 8$

Journal $\quad$ Construction and Building Materials

Volume 116

State $\quad$ Published - Jul 302016

Shon, C. S., Estakhri, C. K., Lee, D., \& Zhang, D. (2016). Evaluating feasibility of modified drilling waste materials in flexible base course construction. Construction and Building Materials, 116, 79-86. DOI: 10.1016/j.conbuildmat.2016.04.100 